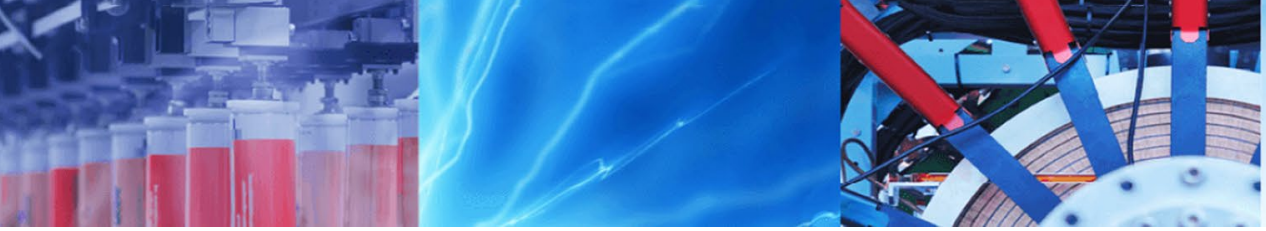

Short Communication

\title{
The electrochemical performance of electrodeposited chitosan bio-nanopolymer in non-aqueous electrolyte: a new anodic material for supercapacitor
}

\author{
V. D. Patake' ${ }^{1}$ T. T. Ghogare ${ }^{1}$ - A. D. Gulbake ${ }^{1}$. C. D. Lokhande ${ }^{1}$
}

() Springer Nature Switzerland AG 2019

\begin{abstract}
The polymeric film electrodes of chitosan are deposited by electrochemical deposition method on the stainless steel substrates. The prepared film electrodes are characterized by X-ray diffraction, scanning electron microscopy, Fourier transform infrared spectroscopy, contact angle techniques and evaluated for the supercapacitor application by studying electrochemical properties through cyclic voltammetry. The XRD study depicts nanocrystalline nature of deposited chitosan with $36 \mathrm{~nm}$ crystallite size. The uniform, compact and spongy chitosan thin film covers the utmost substrate surface and has hydrophilic nature with mean water contact angle $57.9^{\circ}$. The chitosan electrode exhibits $13 \mathrm{~kW} \mathrm{~kg}^{-1}$ power density from the galvanostatic charge discharge study. The chitosan electrode shows the maximum electrochemical capacitance of $36 \mathrm{~F} \mathrm{~g}^{-1}$ in non-aqueous $\mathrm{KCl}$ electrolyte, which presents a new anodic material for supercapacitor application.
\end{abstract}

Keywords Chitosan · Electrodeposition · Polymer · Supercapacitor $\cdot$ Thin film

\section{Introduction}

A capacitor is a device which stores the charges and the capacity is expressed in terms of $\mathrm{C}^{-1}$ and the capacitance in terms of $\mathrm{F} \mathrm{g}^{-1}$. The capacitor which stores the charges in very huge amount is called as supercapacitor. The capacitance of capacitor depends upon area of material exploited as well as the mass of the active material [1-3]. Therefore the capacitance can be expressed in terms of interfacial and specific capacitance.

Many more strategies were exploded to achieve maximum capacitance as well as the stability of the electrode material. The idea of supercapacitor started with the use of carbon nano tube (CNT) which is from the utilization of double layer capacitance [4]. In next stage, it was achieved with transition metal oxides and ferrites [4-8]. These transition metals were again consumed with different sulphides and phosphates to attain extreme capacitance [9-11].
Also the metal oxide based metal organic framework was employed as a new material in supercapacitor application [12]. In the middle, conducting polymers like polyaniline, polypyrole etc. also played an important role in achieving better capacitance [13-15].

From the earlier reports, it is inferred that there was a use of metal based material or artificially synthesized polymer for supercapacitor application. Now keeping in the mind the eco-friendly approach and taking into account of the view of elemental abundance in future, it is a time to find other electrode materials for supercapacitor. In this aspect, chitosan was applied to achieve expected results. The work has been processed by using metal oxide and carbon based material incorporating chitosan. Graphene based porous carbon aerogels on nickel foil displayed a high capacitance of $197 \mathrm{~F} \mathrm{~g}^{-1}$ [16]. Chitosan with activated carbon has high capacitance of $264 \mathrm{~F} \mathrm{~g}^{-1}$ on titanium foil [17]. The chitosan based ternary composite like

C. D. Lokhande, I_chandrakant@yahoo.com | ${ }^{1}$ Centre for Interdisciplinary Research, D.Y. Patil Education Society (Deemed to be University), Kolhapur 416 006, India.

SN Applied Sciences (2019) 1:1063 | https://doi.org/10.1007/s42452-019-1054-7

Received: 18 April 2019 / Accepted: 7 August 2019 / Published online: 21 August 2019

SN Applied Sciences

A SPRINGER NATURE journal 
chitosan-graphene oxide-polyanline on graphite electrode and graphene oxide-chitosan-copper on PET film possess capacitance of $609 \mathrm{~F} \mathrm{~g}^{-1}$ and $356 \mathrm{~F} \mathrm{~g}^{-1}$, respectively [18, 19]. The electrodeposited $\mathrm{MnO}_{2}$-chitosan on nickel foam exhibited $424 \mathrm{~F} \mathrm{~g}^{-1}$ capacitance [20]. Also, the efforts have been made to chitosan based membrane cum binder to improve the capacitance [21].

The literature depicts that chitosan can be a suitable candidate for the supercapacitor and would have highest value of capacitance when incorporated with carbon based materials and metal oxides using the substrates like graphite, nickel foil, nickel foam etc. [16-20]. To the best of our knowledge chitosan has not been yet used as single source as electrode material for the supercapacitor. Chitosan is a linear polysaccharide consists of glucosamine repeating unit with hydroxyl and amine functional groups as shown in Fig. 1 [16, 22]. This is derived from partial N-deacetylation of chitin which is a biopolymer widely distributed in nature and available in insects, crab shell and shrimp shell etc. The animal based polymer-chitosan is versatile biomaterial which has significant application in water purification, cosmetics, and textiles as well as in biomedical field [23-27]. In the present work, chitosan is deposited on low cost stainless steel substrates by electrodeposition. The deposited material is characterized for the structural and morphological information and electrochemical experiments are carried out to find its application in the supercapacitor.

\section{Experimental}

In the present investigation, chitosan films were electrodeposited by using electrochemical analyzer (Model CHI 66E) on stainless steel substrates. Prior to the deposition, stainless steel substrates were polished by zero grade polish paper. After that the substrates were cleaned ultrasonically for $30 \mathrm{~min}$. The deposition of chitosan film was carried out by using chitosan flakes (from shrimp shells 75\% deacetylized) purchased from Loba Chemie Pvt. Ltd.
A chitosan solution was prepared by dissolving chitosan flakes in $1 \%$ acetic acid with $100 \mathrm{mg} / \mathrm{ml}$ weight to volume ratio. It was found that chitosan flakes were initially dispersed in the solvent and dissolved slowly which formed clear and transparent solution. The deposition of chitosan films were carried out from this transparent solution. For the deposition, conventional three electrodes assembly was used in which, graphite electrode was a counter and stainless steel electrode acted as a working electrode, while saturated calomel electrode (SCE) was used as a reference electrode to measure the reaction potentials.

The cathodic deposition was carried out at $-1.5 \mathrm{~V} / \mathrm{SCE}$ on the stainless steel electrode. The films obtained were first cleaned in the doubled distilled water to remove unbounded chitosan and then well dried in the air. The film was thin and transparent, and weighted about $0.00030 \mathrm{~g} \mathrm{~cm}^{-1}$.

The chitosan films were characterized to get the structural and morphological information. The XRD was carried out to recognize the structure and crystallite size of material deposit with the help of Bruker AX5 D8 advance model. The FTIR analysis was conducted by using Alpha T Bruker spectrograph to know the functional groups and hence to confirm the deposited material. The morphology of the material was studied by scanning electron microscope model JEOL JSM-6360. The contact angle of deposited material was obtained using Rame-hart Model A-100. The electrochemical study for supercapacitor was carried out by using ZTV MP1 multichannel electrochemical workstation in the non-aqueous $\mathrm{KCl}$ electrolyte for various scan rates. The stability of electrode was tested to find the reliability of the material in the supercapacitor application.

\section{Results and discussion}

\subsection{Deposition mechanism of chitosan film}

The chitosan films were deposited from chitosan solution on to stainless steel which acted as a working electrode.

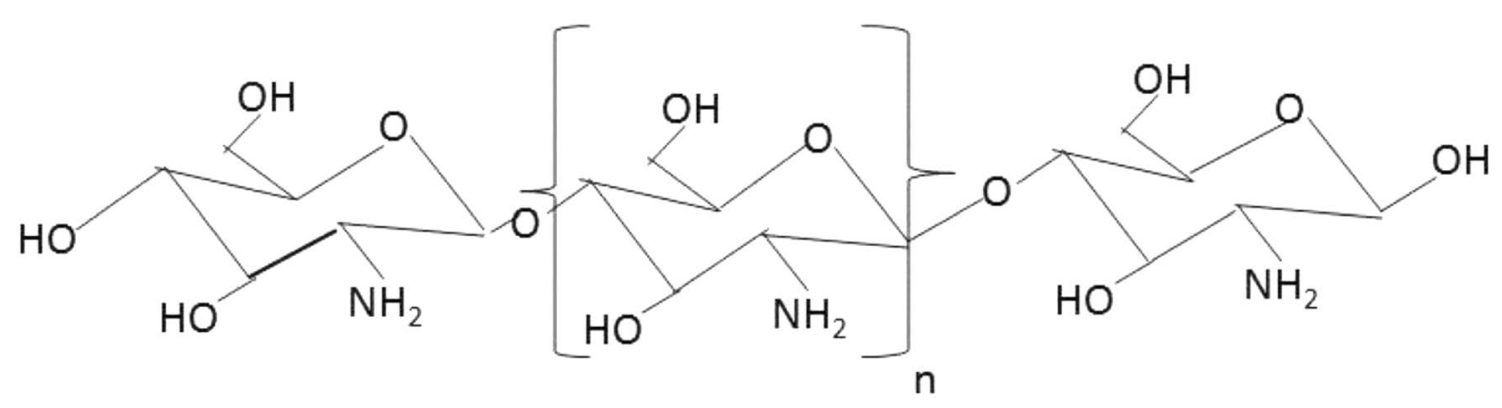

Fig. 1 Chemical structure of chitosan 
The deposition was carried out for $600 \mathrm{~s}$ at $-1.5 \mathrm{~V} / \mathrm{SCE}$ applied potential. In case of chitosan, amine group is protonated $<6.3 \mathrm{pH}$ and becomes a cationic polyelectrolyte [28]. After the application of electric potential, the positively charged molecules of chitosan polymer is attracted towards negatively charged cathode. At that moment chitosan loses its charge and diffuse as chitosan thin film on the substrate as shown in Fig. 2 [16]. The chitosan film observed on the substrate is insoluble due to increase in local pH due to deprotonating of amine group [29]. In brief, a polymeric film of biopolymer has been synthesized by means of one step potentiostatic deposition on low cost stainless steel.

\subsection{XRD study}

In order to know the structure of the deposited material, the X-ray diffraction study is necessary. The X-ray diffraction (XRD) was carried out by using the Cuk $_{\alpha}$ of copper target which produces the diffraction after interaction with the matter on the substrate. Figure 3 provides the structural information of the deposited material. From the figure, the peak at angle $20.3^{\circ}$ indicates the formation of orthorhombic structure of chitosan on the substrate [30]. Similar observation also evidenced for chitosan nanocomposite used for bio-medical application [31]. From the XRD information the crystalline size of the material was calculated using the Sherrer's formula [32]. The calculated value inferred that the synthesized material is nanocrystalline with crystallite size $36 \mathrm{~nm}$.

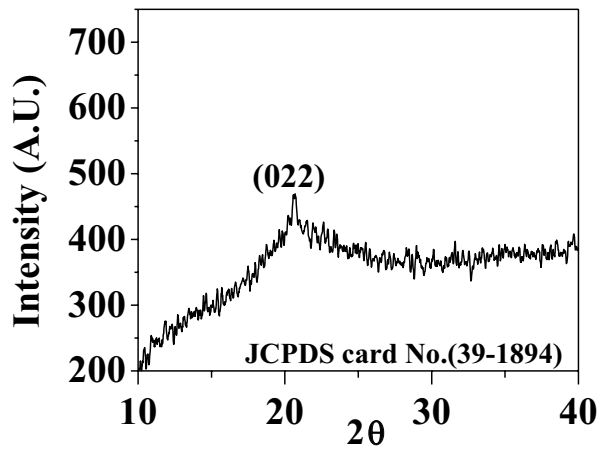

Fig. 3 The XRD of electrodeposited chitosan thin film

\subsection{FTIR study}

The Fourier-transform infrared spectroscopy (FTIR) also supports the formation of the chitosan on the substrate by means of stretching and bending frequencies of functional respective functional group. The FTIR spectrum of chitosan film is shown in Fig. 4. The peaks of different frequencies appeared because of transmitted rays from chitosan in IR region. The figure shows the vibration spectra within the frequencies 750 to $3750 \mathrm{~cm}^{-1}$ corresponding to $\mathrm{N}-\mathrm{H}$ and $\mathrm{O}-\mathrm{H}$ stretching in contribution with intra-molecular hydrogen bonds. The absorption band at around $3364 \mathrm{~cm}^{-1}$ can be attributed to $\mathrm{OH}$ stretching. Further, the presence of $\mathrm{C}=\mathrm{O}$ due to stretching of amide group is confirmed around the signal at $1646 \mathrm{~cm}^{-1}$. Also the spectrum at around $1255 \mathrm{~cm}^{-1}$ is because of the bending vibrations of hydroxyl group

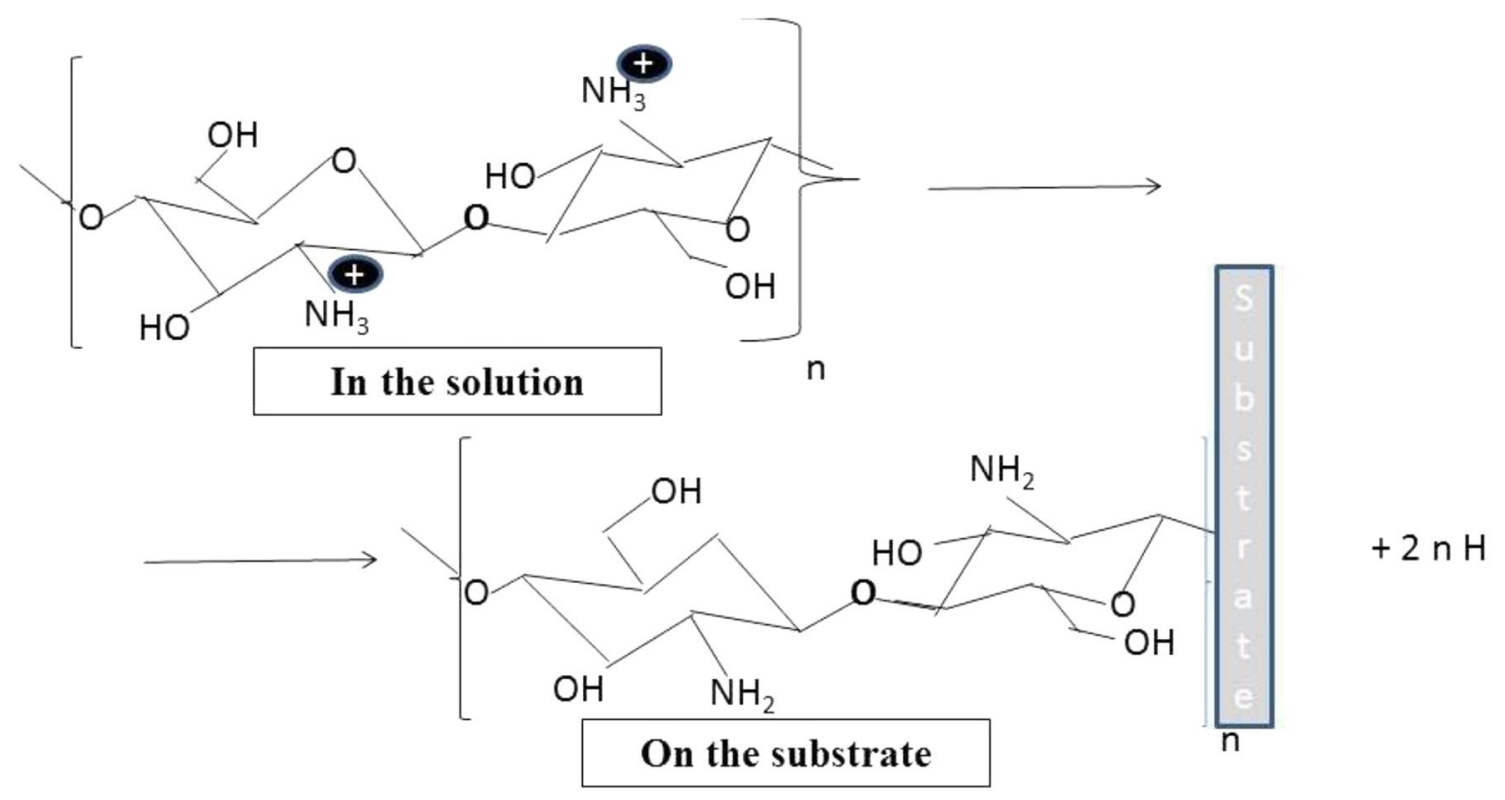

Fig. 2 The deposition mechanism of chitosan on the substrate 


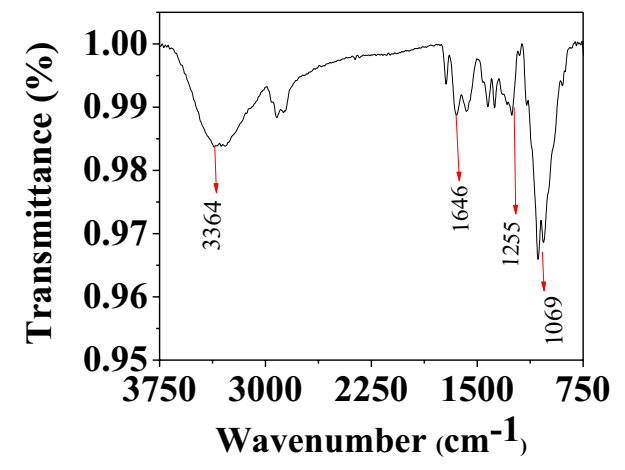

Fig. 4 The FTIR spectrum of as deposited chitosan film

present in the chitosan. The absorption band arrived at $1069 \mathrm{~cm}^{-1}$ corresponds to $\mathrm{C}-\mathrm{O}$ band stretching of chitosan sample. The spectrum obtained in present work has close resemblance with the spectra of chitosan samples described by others in literature $[33,34]$.

\subsection{Scanning electron microscopy}

The chitosan thin film material is delicate one and found to be burned at high electron energy. To overcome this situation the scanning electron microscopic study was carried out at $10 \mathrm{kV}$ applied potential. Figure 5 shows the scanning electron microscopy of the chitosan thin film carried out to study the morphology of the material. The figure shows uniform and compact like morphology of chitosan film spreads over the entire substrate at $205 x$ and $500 \times$ magnifications (in the inset). Sincerely looking insight to the morphology, sponge like appearance with large number of pores is observed which are beneficial for the rapid conduction of ions inside the active material to improve the supercapacitance.

\subsection{Contact angle and electrochemical study}

The water contact plays an important role in achieving capacitance by means of electron transfer through the

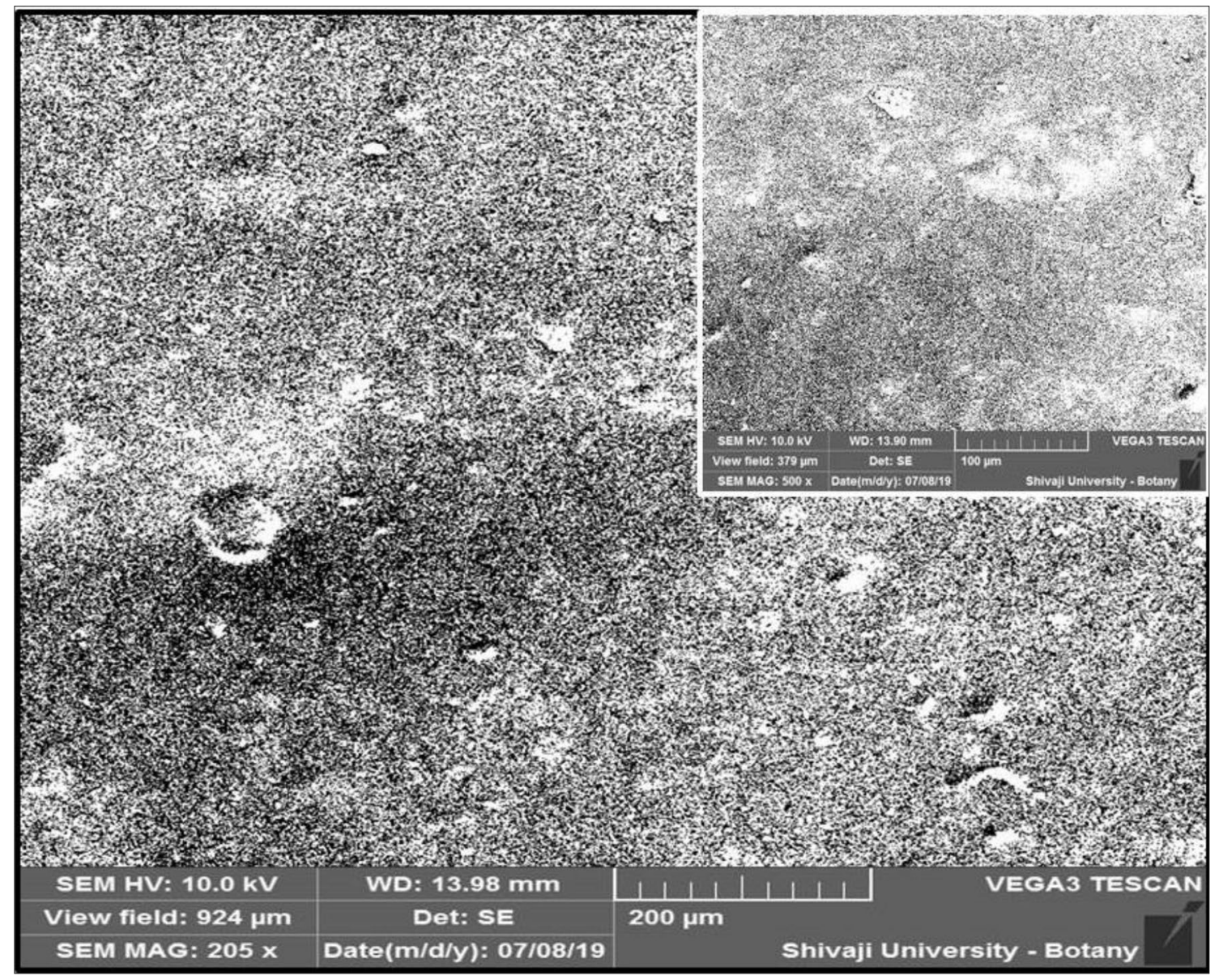

Fig. 5 The scanning electron micrographs (SEM) of chitosan film at $205 \times$ magnification and $500 \times$ (in the inset)

SN Applied Sciences

A SPRINGER NATURE journal 


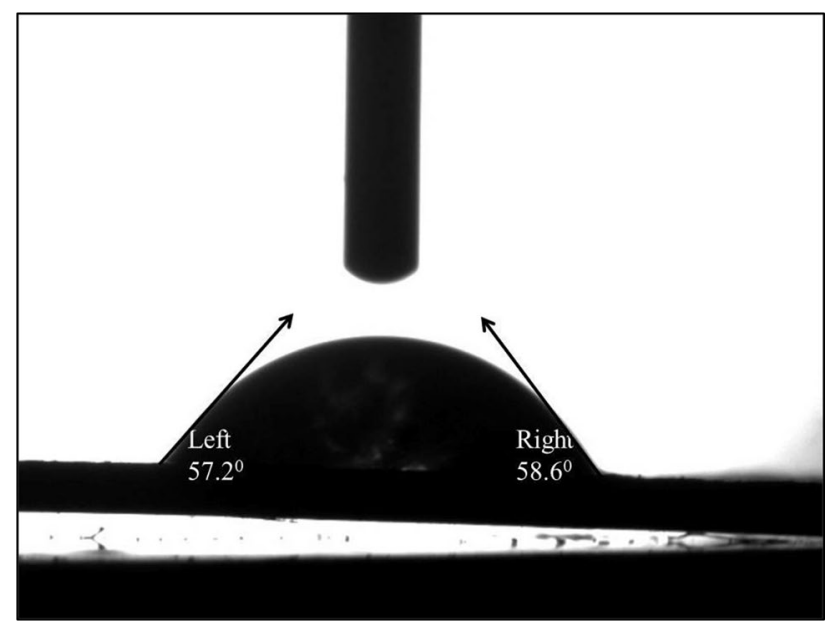

Fig. 6 The contact angle of chitosan film

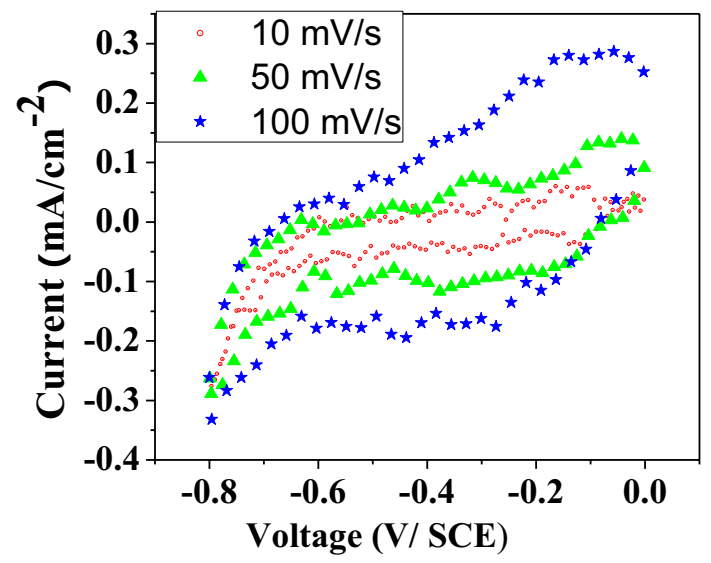

Fig. 7 Cyclic voltammetry (CV) study of chitosan electrode (Film thickness $0.00030 \mathrm{~g} \mathrm{~cm}^{-1}$ )

electrolyte. Figure 6 shows the contact angle of $57.9^{\circ}$ depicting hydrophilic nature of the film.

To study the electrochemical performance of chitosan electrode, the cyclic voltammetry (CV) study was carried out in traditional three electrode system. In the system chitosan electrode, platinum mesh and SCE acted as working, counter and reference electrodes, respectively. The CV plots studied at different scan rates from 5 to $100 \mathrm{mV} \mathrm{s}^{-1}$ are shown in Fig. 7. Figure shows that there is an increase in the current with an increase in the scan rate with redox peaks. The redox peaks are due the intercalation and deintercalation of the charges into the active sites. In the chitosan, hydroxyl $(-\mathrm{OH})$ and amino $\left(-\mathrm{NH}_{2}\right)$ are reactive functional groups. These groups might be responsible for the capacitive behavior of chitosan electrode by protonation and de-protonation. The chitosan electrode carries excess positive charge which acts as cationic natural polymer due to $\mathrm{NH}_{3}{ }^{+}$group [35]. The transfer of species for the conduction of current can be shown from following reactions (I-III) which are responsible for the production of pseudocapacitance. In the proposed reaction, the first reaction shows the hyperpositive chitosan reacts with electron which turns in the formation of amine with $\mathrm{H}_{2}$ evolution. This type of reduction reaction occurred in potential range of -0.6 to $-0.3 \mathrm{~V} / \mathrm{SCE}$. The reduction peaks is due to the electron transfer and hydrogen evolution. In next reactions, $\mathrm{OH}$ group consumes electron and becomes negative charged with a reduction peak in between -0.3 and $-0.1 \mathrm{~V} / \mathrm{SCE}$. These reactions are reversible and show the oxidation peaks in the reverse scan. As the scan rate increases multiple redox peaks disappear and can be seen integrated within the said potential range.

$$
\begin{aligned}
& 2 \text { Chitosan- } \mathrm{NH}_{3}^{+}+2 \mathrm{e}^{-} \leftrightarrow 2 \text { Chitosan- }\left(\mathrm{NH}_{2}\right)+\mathrm{H}_{2} \uparrow \\
& \text { Chitosan-OH }+\mathrm{e}^{-} \leftrightarrow \text { Chitosan-OH } \\
& \text { Chitosan- } \mathrm{OH}^{-}+\mathrm{H}^{+} \leftrightarrow \text { Chitosan-OH }
\end{aligned}
$$

The capacitance or interfacial capacitance (C) from the CV plots are calculated by using the formula,

$C=\frac{\int I}{V \times\left(\frac{d v}{d t}\right)}$

where $\int I$-current, $V$ - potential window and $\left(\frac{d v}{d t}\right)$ - scan rate.

The unit of specific capacitance $\left(C_{s}\right)$ is $\mathrm{F} \mathrm{g}^{-1}$ which is obtained by using the weight of the electrode material (W) given by,

$C_{s}=\frac{C}{W}$

The different values for the supercapacitor study have been calculated for the chitosan electrode using above formula are shown in Table 1.

The stability of electrode was tested at $5 \mathrm{mV} \mathrm{s}^{-1}$ scan rate to find the potential application in supercapacitor for 5000 cycles as shown in Fig. 8. The cyclic voltammetric study shows that curves are symmetric. After 5000 cycles the percentage retention observed is $85 \%$ which may be because of loss of active sites during the cycling.

The galvanostaic charge-discharge (GCD) curves of the supercapacitor recorded in the potential range of $0-0.8 \mathrm{~V}$ and at a current densities of $0.3,0.5,0.6,0.8,0.9$ and $1 \mathrm{~mA} \mathrm{~cm}^{-2}$ are shown in Fig. 9. It is observed that the discharging time decreases with increase in current density which results in increased power density as shown in Table 2. From the GCD curves, the power density is calculated by using the formula $(3)[36,37]$, 
Table 1 Supercapacitance study of chitosan electrode from cyclic voltammetry

\begin{tabular}{lcl}
\hline Sr. no & Scan rate $\left(\mathrm{mV} \mathrm{s}^{-1}\right)$ & $\begin{array}{l}\text { Specific } \\
\text { capacitance } \\
\left(\mathrm{F} \mathrm{g}^{-1}\right)\end{array}$ \\
\hline 1 & 5 & 36 \\
2 & 10 & 17 \\
3 & 20 & 9 \\
4 & 50 & 6 \\
5 & 100 & 5 \\
\hline
\end{tabular}

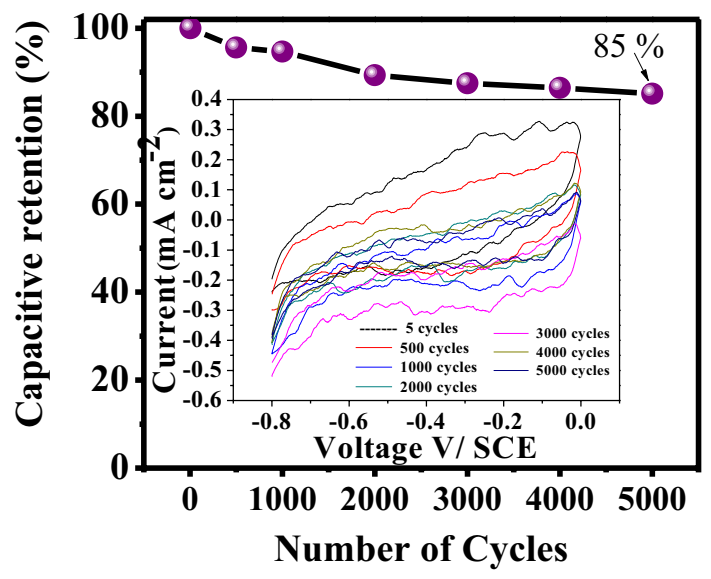

Fig. 8 Cyclic stability and capacitive retention of chitosan electrode for 5000 cycles

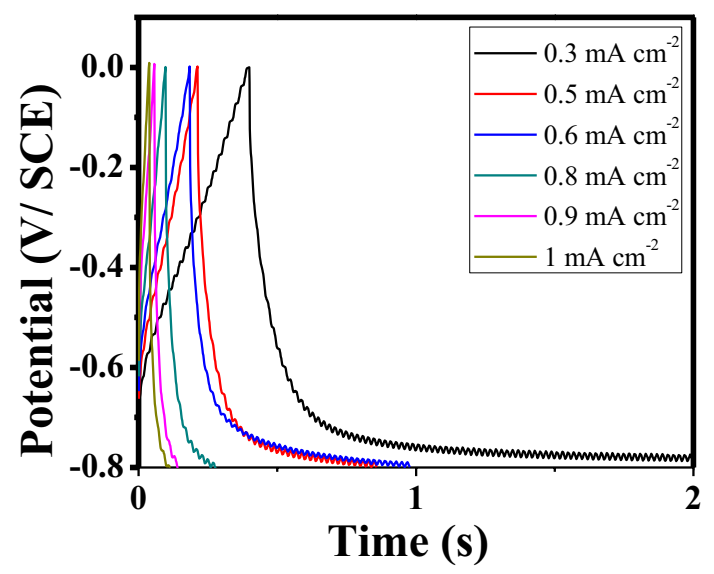

Fig. 9 Galavanostatic charge-discharge (GCD) study of chitosan electrode

$\mathrm{P}=\frac{E \times 3600}{T_{d}}$

where, $T_{d}$ is discharging time, $E=\frac{0.5 \times \operatorname{cs} \times\left(v^{2} \mathrm{max}-v^{2} \mathrm{~min}\right)}{3.6}$, $V m a x$ and $V$ min are the maximum and minimum potential
Table 2 Power density of chitosan electrode from galvaostatic charge-discharge

\begin{tabular}{llll}
\hline Sr. no & $\begin{array}{l}\text { Current density } \\
\left(\mathrm{mA} \mathrm{cm}^{-2}\right)\end{array}$ & $\begin{array}{l}\text { Discharging } \\
\text { time }(\mathrm{s})\end{array}$ & $\begin{array}{l}\text { Power } \\
\text { density } \\
\left(\mathrm{kW} \mathrm{kg}^{-1}\right)\end{array}$ \\
\hline 1 & 0.3 & 5.55 & 4 \\
2 & 0.5 & 0.65 & 6 \\
3 & 0.6 & 0.61 & 8 \\
4 & 0.8 & 0.18 & 10 \\
5 & 0.9 & 0.08 & 12 \\
6 & 1.0 & 0.07 & 13 \\
\hline
\end{tabular}

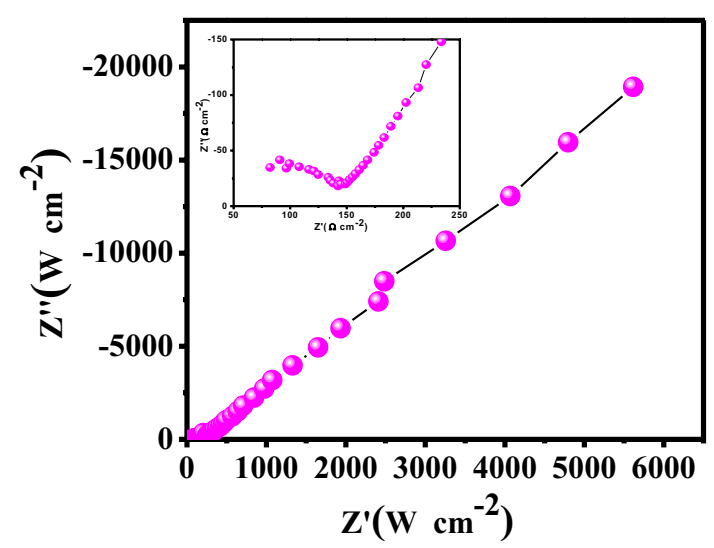

Fig. 10 Electrochemical impedance (EIS) spectra of chitosan electrode. Inset shows the semicircle

during the discharge, and $C_{s}=\frac{\mid x \Delta t}{\Delta v}$ where, l-current density, $\Delta t$-time of discharge, $\Delta v-$ potential range

The maximum power density is attained to be $13 \mathrm{~kW} \mathrm{~kg}^{-1}$ at $1 \mathrm{~mA} \mathrm{~cm}{ }^{-2}$ current density. The variation of power density with applied current with the discharging time is shown in Table 2.

The electrochemical impedance spectroscopy data for the chitosan electrode is expressed as Nyquist plot over the frequency range of 0.1 to $10^{3} \mathrm{~Hz}$ as shown in Fig. 10 . This figure shows the small semicircle (inset of Fig. 10) in the first segment, followed by a vertical line. In the high frequency region, the relatively small semicircle represents the dominant resistive nature of the supercapacitor system consisting of electrode-electrolyte and current-collector. At the starting point of the semicircle, line represents the resistance (Rs) of the electrolyte in contact with the current collector and electrode called as series resistance.

In electrochemical reaction, electrons transferred in the electrode possess some resistance called as charge transfer resistance as $R_{c t}$. The minimum $R_{c t}$ is required for the best electrochemical behavior [38]. In the present case more Rct may results into low capacitance of the material. 
The specific capacitance and power density of the material can be increased by increasing the material deposit and obtaining the proper composite with other anodic materials on the low resistance substrates [16-20]. After the electrochemical study, it can be concluded that the chitosan thin film electrode is an anodic material which has potential application in supercapacitor.

\section{Conclusions}

A new polymeric material, chitosan from biological source has been electrodeposited on the low cost stainless steel substrate. The material has orthorhombic structure and uniform and compact as well as spongy morphology. The chitosan has water contact angle of $57.9^{\circ}$ depicting hydrophilic nature. It has potential application in supercapacitor as examined from electrochemical studies. The electrode shows maximum capacitance of $36 \mathrm{~F} \mathrm{~g}^{-1}$ and power density $13 \mathrm{~kW} \mathrm{~kg}^{-1}$ in non-aqueous methanol electrolyte.

Acknowledgements Authors are thankful to Department of Science and Technology (DST), New Delhi India for their financial support through research Project No. DST/TMD/MES/2K17/04 dated 7th July, 2018

\section{Compliance with ethical standards}

Conflict of interest On behalf of all authors, the corresponding author states that there is no conflict of interest.

\section{References}

1. Ho MY, Khiew PS, Isa D, Tan TK (2014) A review of metal oxide composite electrode materials for electrochemical capacitors. Nano Brief Rep Rev 9:1430002

2. Wang F, Wu X, Yuan X, Liu Z, Zhang Y, Fu L, Zhu Y, Zhou Q, Wu Y, Huang $W$ (2017) Latest advances in supercapacitors: from new electrode materials to novel device designs. Chem Soc Rev 46:6816

3. Dubal DP, Ayyad O, Ruiz V, Romero PG (2015) Hybrid energy storage: the merging of battery and supercapacitor chemistries. Chem Soc Rev 44:1777

4. Chen T, Dai L (2013) Carbon nanomaterials for high-performance supercapacitors. Mater Today 16:272

5. Ci S, Wen Z, Qian Y, Mao S, Cui S, Chen J (2015) NiO-microflower formed by nanowire-weaving nanosheets with interconnected $\mathrm{Ni}$-network decoration as supercapacitor electrode. Sci Rep 5:1

6. Huang M, Li F, Dong F, Zhang YX, Zhang LL (2015) $\mathrm{MnO}_{2}$-based nanostructures for high-performance supercapacitors. J Mater Chem A 3:21380

7. Vignesh V, Subramani K, Sathish M, Navamathavan R (2018) Electrochemical investigation of manganese ferrites prepared via a facile synthesis route for supercapacitor applications. Colloids Surf A 538:668

8. Elkholy AE, El-Taib Heakal F, Allam NK (2017) Nanostructured spinel manganese cobalt ferrite for high-performance supercapacitors. RSC Adv 7:51888
9. Wei W, Mi L, Gao Y, Zheng Z, Chen W, Guan X (2014) Partial ionexchange of nickel-sulfide-derived electrodes for high performance supercapacitors. Chem Mater 26:3418

10. Liu M, Li J, Han W, Kang L (2016) Simple synthesis of novel phosphate electrode materials with unique microstructure and enhanced supercapacitive properties. J Energy Chem 25:601

11. Ghogare TT, Lokhande AC, Pujari RB, Lokhande CD (2019) Lanthanum sulfide/graphene oxide composite thin films and their supercapacitor application. SN Appl Sci 1:110

12. Hosseini MG, Shahryari E (2017) A novel high-performance supercapacitor based on chitosan/graphene oxide-MWCNT/ polyaniline. J Colloids Interface Sci 496:371

13. Eftekhari A, Li L, Yang Y (2017) Polyaniline supercapacitors. J Power Sources 347:86

14. Huang Y, Li H, Wang Z, Zhu M, Pei Z, Xue Q, Huang Y, Zhi C (2016) Nanostructured polypyrrole as a flexible electrode material of supercapacitor. Nano Energy 22:422

15. Ambade RB, Ambade SB, Shrestha NK, Nah YC, Han SH, Lee $\mathrm{W}$, Lee SH (2013) olythiophene infiltrated $\mathrm{TiO}_{2}$ nanotubes as high-performance supercapacitor electrodes. Chem Commun 49:2308

16. Hassan S, Suzuki M, El-Monein AA (2014) Synthesis of $\mathrm{MnO}_{2}-\mathrm{chi}-$ tosan nanocomposite by one-step electrodeposition for electrochemical energy storage application. J Power Sources 246:68

17. Hao P, Zhao Z, Leng Y, Tian J, Sang Y, Boughton RI, Wong CP, Liu $H$, Yang B (2015) Graphene-based nitrogen self-doped hierarchical porous carbon aerogels derived from chitosan for high performance supercapacitors. Nano Energy 15:9

18. Lee DY, Yoon SJ, Shrestha NK, Lee SH, Ahm H, Han SH (2012) Unusual energy storage and charge retention in co-based metalorganic-frameworks. Microporous Mesoporous Mater 153:163

19. Selvam S, Balamuralitharan B, Jegatheeswaran S, Kim MY, Karthick SN, AnadhaRaj J, Bhoomi P, Sundrarajan M, Prabhakar K, Kim HJ (2017) Electrolyte-imprinted graphene oxide-chitosan chelate with copper crosslinked composite electrodes for intense cyclic-stable, flexible supercapacitors. J Mater Chem A $5: 1380$

20. Raja M, Sadhasivam B, Naik J, Dhamodharan R, Kothandaraman $R$ (2019) A chitosan/poly (ethylene glycol)-ran-poly (propylene glycol) blend as an eco-benign separator and binder for quasisolid-state supercapacitor applications. Sust Energy Fuel 3:760

21. Genovese M, Wu H, Virya A, Li J, Shen P, Lian K (2018) Ultrathin all-solid-state supercapacitor devices based on chitosan activated carbon electrodes and polymer electrolytes. Electrochim Acta 273:392

22. Rinaudo M (2006) Chitin and chitosan: properties and applications. Prog Polym Sci 31:603

23. Turunen J, Karppinen A, Ihme R (2019) Effectiveness of biopolymer coagulants in agricultural wastewater treatment at two contrasting levels of pollution. SN Appl Sci 1:210

24. Gerente C, Lee VKC, Le Cloirec P, McKAY G (2007) Application of chitosan for the removal of metals from wastewaters by adsorption-mechanisms and models review. Crit Rev Environ Sci Technol 37:41

25. Dutta PK, Dutta J, Tripathi VS (2004) Chitin and chitosan: chemistry, properties and applications. J Sci Ind Res 63:20

26. Rinaudo M (2006) Chitin and chitosan: properties and applications. Prog Polym Sci 31:603

27. Komi DE-A, Hamblin MR (2016) Chitin and chitosan: production and application of versatile biomedical nanomaterials. Int J Adv Res 4:411

28. Zangmeister RA, Park JJ, Rubloff GW, Tarlov MJ (2006) Electrochemical study of chitosan films deposited from solution at reducing potentials. Electrochim Acta 51:5324

29. Winkler TE, Ben-Yoav H, Chocron SE, Kim E, Kelly DL, Payne GF, Ghodssi R (2014) Electrochemical study of the catechol-modified 
chitosan system for clozapine treatment monitoring. Langmuir 30:14686

30. Joint Committee on Powder Diffraction Standards (JCPDS) Card No. 39-1894

31. EINahrawy AM, AbouHammad AB (2016) A facile co-gelation sol gel route to synthesize cao: $\mathrm{P}_{2} \mathrm{O}_{5}: \mathrm{SiO}_{2}$ xerogel embedded in chitosan nanocomposite for bioapplications. Int J PharmTech Res 9:16

32. Anitha SN, Jayakumari I (2015) Synthesis and analysis of nanocrystalline $\mathrm{Fe}_{2} \mathrm{Mn}_{2} \mathrm{Ni}_{0.5} \mathrm{Zn}_{1.5} \mathrm{O}_{9}$ at different treating temperatures. J Nanosci Technol 1:26

33. Govindan S, Nivethaa EAK, Saravanan R, Narayanan V, Stephen A (2012) Synthesis and characterization of chitosan-silver nanocomposite. Appl Nanosci 2:299

34. Queiroz MF, Melo KRT, Sabry DA, Sassaki GL, Rocha HAO (2015) Does the use of chitosan contribute to oxalate kidney stone formation? Mar Drugs 13:141

35. Darder M, Colilla M, Ruitz-Hitzky E (2005) Chitosan-clay nanocomposites: application as electrochemical sensors. Appl Clay Sci 28:199
36. Prabaharan SRS, Vimala R, Zainal Z (2006) Nanostructured mesoporous carbon as electrodes for supercapacitors. J Power Sources 161:730

37. Pujari RB, Lokhande AC, Shelke AR, Kimb JH, Lokhande CD (2017) Chemically deposited nano grain composed $\mathrm{MoS}_{2}$ thin films for supercapacitor application. J Colloids Interface Sci 496:1

38. Pandit B, Dubal DP, Sankapal BR (2017) Large scale flexible solid state symmetric supercapacitor through inexpensive solution processed $\mathrm{V}_{2} \mathrm{O}_{5}$ complex surface architecture. Electrochim Acta 242:382

Publisher's Note Springer Nature remains neutral with regard to jurisdictional claims in published maps and institutional affiliations. 